\title{
EXCLUDABLE AND NON-EXCLUdABLE PUBLIC INPUTS: CONSEQUENCES FOR ECONOMIC GROWTH
}

\author{
INGRID OTT \\ STEPHEN J. TURNOVSKY
}

CESIFO WORKING PAPER NO. 1423

CAtegory 5: Fiscal Policy, Macroeconomics and Growth MARCH 2005 


\title{
EXCLUDABLE AND NON-EXCLUDABLE PUBLIC INPUTS: CONSEQUENCES FOR ECONOMIC GROWTH
}

\begin{abstract}
Many public goods are characterized by rivalry and/or excludability. This paper introduces both non-excludable and excludable public inputs into a simple endogenous growth model. We derive the equilibrium growth rate and design the optimal tax and user-cost structure. Our results emphasize the role of congestion in determining this optimal financing structure and the consequences this has in turn for the government's budget. The latter consists of fee and tax revenues that are used to finance the entire public production input and that may or may not suffice to finance the entire public input, depending upon the degree of congestion. We extend the model to allow for monopoly pricing of the user fee by the government. Most of the analysis is conducted for general production functions consistent with endogenous growth, although the case of CES technology is also considered.
\end{abstract}

JEL Code: H21, H40, O40.

Keywords: excludable and non-excludable public goods, congestion, growth.

Ingrid Ott

University of Lueneburg

Department of Economics

Scharnhorststr. 1

Bldg. 4, Room 204

21332 Lueneburg

Germany

ott@uni-lueneburg.de
Stephen J. Turnovsky

University of Washington

Department of Economics

Box 353330

Seattle, WA 98195

USA

sturn.@u.washington.edu

This paper was begun when Ingrid Ott visited the University of Washington. Stephen Turnovsky's research was supported in part by the Castor endowment at the University of Washington. 


\section{Introduction}

A vast literature has evolved emphasizing the role of public investment as a determinant of economic growth. Among the earliest contributions Arrow and Kurz (1970) is particularly significant, while the seminal work of Barro (1990) has been especially influential with respect to the contemporary endogenous growth literature. Much of the literature, including Barro, treats the public input as a pure public good, freely available without restrictions or impediments to all agents in the economy. However, the public goods literature identifies many different characteristics that most public goods in fact exhibit, notably the presence of "rivalry” and/or "excludability"; see e.g. Cornes and Sandler (1996). Thus the treatment of a public input as a pure public good is extreme, as has been long acknowledged. ${ }^{1}$

In response to this, much of the recent literature analyzing the impact of public expenditure and investment on economic growth allows for non-excludable public goods that, because of congestion, are nevertheless subject to rivalry. Several alternative formulations of congestion have been adopted; see e.g. Barro and Sala-i-Martin (1992), Glomm and Ravikumar (1994), Turnovsky (1996, 2000), and Eicher and Turnovsky (2000). In particular, Eicher and Turnovsky emphasize the restrictions that must be imposed on the form of congestion function if an endogenous growth model is to sustain an equilibrium balanced growth path.

In addition to rivalry, a second key feature of a many public goods is excludability. This means that individuals have access to the good if and only if they are willing to pay the "user fee" for the service it provides. The costs of using the input may thus be unequivocally assigned to the users, something that is not possible for a pure public good, and potential users will be denied access to it unless they are willing to pay the necessary fee. Under this financing scheme market provision of the public input is basically possible. Examples of public goods that are often excludable include: highways, schools, universities, national parks, and television, which may require fees or licenses. In addition, publicly provided private goods, like water or electric power supply for which governments levy user fees, also exist.

\footnotetext{
${ }^{1}$ For example, Thompson (1974) argues that even national defense, often regarded as the prototypical pure public good, is subject to a form of congestion.
} 
In contrast to the treatment of rivalry, the consequences of excludability of public goods and its financing by a user cost, as well as the choice between tax financing and user cost financing for economic growth has received little attention, despite its practical importance, particularly in European countries. Ott (2001) focuses on the growth impact of an entirely excludable public production input subject to potential congestion. The optimal financing implications are derived for a government that provides the public input at competitive prices. The monopolistic provision of excludable public goods has been discussed by Brito and Oakland (1980), although not in the context of growth models.

The objective of the present paper is to develop a growth model that includes both excludable and non-excludable public goods as productive inputs, both of which may be subject to some degree of congestion. What we have in mind is the following. A firm, as part of its production process, needs to ship its finished output to market. It has the choice of using a highway, for which it pays a user fee, or using a surface road that runs parallel and that is financed out of tax revenues. The two roads are clearly substitutes in the productive process and the important question is the optimal provision of the two forms of public input and their pricing structure. Two main features distinguish our analysis from previous contributions: first, the introduction of partial excludability of the productive public input, and second the possibility of monopolistic pricing by the government in an economy experiencing ongoing growth.

The provision of a publicly provided infrastructure that is characterized by exclusion is quite widespread and is therefore a plausible assumption. Within the European Union, different systems for financing infrastructure exist: While some countries levy tolls only for trucks, other countries also charge private individuals for the use of the infrastructure. In addition, highway toll systems differ in their design from country to country: While some tolls are time-based (see the EuroVignette-System in Belgium, Denmark, Luxembourg, The Netherlands and Sweden), others are based on distance (see e.g. Germany, Austria, Italy or France). With the introduction of the user fee system in Germany a transition from tax to fee financing for the provision and maintenance of infrastructure is put in place. In addition, though still tentative, the introduction of highway user fees for private individuals is under discussion. Due to the new toll collection system this would not pose 
any technical problems and exclusion is enforceable at very low costs. ${ }^{2}$

While in most countries taxation still account for the largest part of government revenues, in many countries there has been a recent trend toward more user fees; see e. g. Wassmer and Fisher (2002) for the United States or European Commission (2001) for the EU. Levying fees enables governments to pursue different goals. The two main reasons in favor of fees mentioned in the literature are: a revenue effect and an incentive effect.

Several arguments have been advanced in support of the revenue effect. First, user fees may increase total government revenues and thus reduce budget deficits. This requires that charging user fees does not simply lead to a different structure of government revenues in favor of fees, but in fact, generates additional sources of revenue. A second argument arises in the context of privatization debates; see Megginson and Netter (2001). Aside from efficiency gains within public enterprises, the key objective is to improve the financial position of governments, particularly in cases where they have been unwilling or unable to continue to finance deficits in the public sector (e. g. in accordance with the Maastricht criteria). A third argument involves international tax competition. Increasing globalization is inducing pressure to reduce taxation on mobile factors, as those factors can move to countries having the lowest taxes, thus reducing the tax base and government revenue. This might result in a policy to shift taxes from mobile to immobile tax bases or to move from tax to fee revenues. The latter requires that exclusion is possible and that the total impact of this policy on the generated revenues is positive. With regard to the incentive effect, the user fee may reduce congestion that arises with a suboptimal high usage of the public input. Second, it may internalize negative externalities arising from other sources of economic activity.

The model we employ is a straightforward extension of the Barro (1990) model, modified to include both a conventional non-excludable public input, financed out of tax revenues, plus an excludable public input that requires a user fee. Both goods are rival, which we specify by introducing congestion. Our main results are presented as a series of propositions describing the interaction between these two forms of input, both in production, and with respect to their financing.

\footnotetext{
${ }^{2}$ Another example of infrastructure that is excludable, but nevertheless still predominantly provided by governments, is airports. The structure of airport ownership of in Europe is quite diverse. While the British Airport Authority privatized their entire airport system, on the European continent at most $50 \%$ of any airport is owned by private agents. The excludability arises from the need to purchase landing rights to use the airport.
} 
Beginning with a centrally planned economy we derive the first-best optimal shares of the two forms of public inputs, as a benchmark. The first key result is to characterize the structure of the optimal income tax and user fee that will replicate the first-best equilibrium. These are expressed in terms of: (i) the partial production elasticities of the two inputs, and (ii) their respective degrees of congestion. We show how the existence of congestion in either input raises the income tax and lowers the user fee. We then briefly turn to the case where the government provides non-optimal amounts of the public inputs and characterize the tax-user fee structure that is necessary to correct for the two externalities that arise in that case: (i) the non-optimal provision of the public good, and (ii) the congestion effects.

We examine in detail the implications of tax versus user-fee financing for the government's budget. In particular we find that the user fee will fully finance the excludable input if and only if there is no congestion. Whether or not the total revenue generated - taxes plus user fee - suffice to finance the government's overall budget depends critically upon the degrees of congestion, in both types of government input.

The fact that the government is the unique supplier of the public input presents it with the opportunity to price as a monopolist in the case of the excludable input. While this turns out to have no effect on optimal tax policy, it does have important consequences for the setting of the user fee and thus for the overall revenue. Indeed, we find that it can now fully finance the excludable input out from the user fee if the degree of monopoly power equals or exceeds the optimal tax rate.

The remainder of the paper is structured as follows. After setting out the underlying analytical structure in Section 2, the next section derives the equilibrium in the centrally planned economy. Section 4 then derives the equilibrium in the decentralized economy, while Section 5 provides a general characterization of the optimal tax and pricing policies. These have consequences for the government budget and these are spelled out in Section 6. The extension to allow for monopoly pricing by the government is undertaken in Section 7. Until this point our analysis is based on the most general production function, consistent with sustaining on-going growth. All that this requires is that it be constant returns to scale in the three productive inputs, private capital and the two public inputs. Section 8 briefly discusses the special case of the constant elasticity of 
substitution production function, thus enabling us to focus explicitly on the role of factor substitutability. Section 9 concludes, while technical details are relegated to the appendix.

\section{The Analytical Framework}

\subsection{Production technology and public inputs}

The economy is populated by $n$ identical individuals who consume and produce a single good. Individual output is determined by privately owned capital, $k$, and the aggregate flow of public services. The individuals may be excluded from at least a part of these services. To capture the feature of excludability the public input is split in an excludable part, $E_{S}$, and a non-excludable component, $G_{S}$. The individual agent's production function

$$
y=F\left(k, E_{S}, G_{S}\right)
$$

is homogeneous of degree one in the three inputs. ${ }^{3}$ It is assumed that the productive services derived by the representative individual from a given amount of public expenditure depend upon the usage of his individual capital stock relative to aggregate usage. This describes the situation of relative congestion that is introduced via typical congestion functions; see e.g. Barro and Sala-i-Martin (1992), Eicher and Turnovsky (2000):

$$
\begin{array}{ll}
E_{S}=E\left(\frac{k}{K}\right)^{\varepsilon_{E}} & 0 \leq \varepsilon_{E} \leq 1 \\
G_{S}=G\left(\frac{k}{K}\right)^{\varepsilon_{G}} & 0 \leq \varepsilon_{G} \leq 1
\end{array}
$$

where $K=n k$ denotes the aggregate stock of private capital. ${ }^{4}$ The exponents $\varepsilon_{E}$ and $\varepsilon_{G}$ parameterize the degree of congestion for either component of the public production input. The case $\varepsilon_{E}=\varepsilon_{G}=0$ corresponds to nonrival pure public inputs that, independent of the size of the economy,

\footnotetext{
${ }^{3}$ We assume that labor is supplied inelastically.

${ }^{4}$ Eicher and Turnovsky (2000) discuss at some length alternative specifications of congestion, some of which has its genesis in the urban economics literature; see e.g. Edwards (1990). They draw the distinction between "relative" congestion, as specified in (2), and “absolute" congestion, where (2a), for example would be of the form $E_{S}=E K^{-\chi}$ say. As Eicher and Turnovsky note, since unlike relative congestion, absolute congestion is in general inconsistent with endogenous growth, we adopt the specification given in (2).
} 
are fully available to each individual. There is no congestion. The other limit, $\varepsilon_{E}=\varepsilon_{G}=1$, reflects a situation of proportional (relative) congestion. Given an agent's individual capital stock, only if $E$ and $G$ increase at the same rate as does the economy, as measured by the aggregate capital stock, do the levels of service provided to any individual remain constant. The public good is then like a private good in that since $K=n k$, each of the $n$ individuals receives his proportionate share of the service; $E_{S}=E / n .^{5}$ The cases $0<\varepsilon_{E}<1,0<\varepsilon_{G}<1$ reflect situations of partial (relative) congestion, in the sense that given the individual stock of capital, government spending can increase at slower rate than does $K$ and still provide a fixed level of services to the firm. ${ }^{6}$

\section{$2.2 \quad$ Fiscal instruments and monopoly power}

To finance the provision of the public input the government needs to raise revenues. Most growth models with public inputs assume non-excludability, so that the only way to finance the provision of these goods is through taxes. ${ }^{7}$ An important feature of the model developed here is that the government has at its disposal an additional fiscal instrument. Because of the possibility of exclusion, the government may levy user fees on the individual usage, $E$, that reflect the price each individual has to pay if it decides to employ $E$ for production. As will be shown later, the optimal user fee will equal the marginal cost of provision. But one also has to take into account that the government might behave as a monopoly in the provision of the excludable public good. Monopoly power is formalized via the degree of monopoly, denoted by $\omega$, that reflects the negative reciprocal of the price elasticity of demand for $E$. We shall denote the user fee by $q$, while $\tau$ and $l$ are the (distortionary) taxes on income and a (non-distortionary) lump sum tax levied on each individual, respectively. The government is assumed to balance its budget in each period. With these assumptions (total) government revenues are given by

\footnotetext{
${ }^{5}$ As a terminological point, Barro and Sala-i-Martin (1992) describe the public service in this case as being excludable.

${ }^{6}$ Although we do not discuss this case, we should not necessarily rule out congestion parameters in excess of unity. This describes a situation where congestion is so great that the public good must grow faster than the economy in order for the level of services provided to remain constant. This case is unlikely at the aggregate level, but may well be plausible for local public goods (see Edwards 1990).

${ }^{7}$ See e.g. Barro (1990), Rebelo (1991) and Futagami et al. (1993). Some analyses also allow for government borrowing, which typically is equivalent to lump-sum tax financing; see e.g. Turnovsky (1976), Ireland (1994), and Bruce and Turnovsky (1999)
} 


$$
G_{r e v}(\tau, l, q(\omega))=n \tau y+n q(\omega) E+n l
$$

\subsection{Aggregate resource constraint}

Output can be either consumed, used for the provision of the public inputs, or accumulated as capital. Thus, the aggregate resource constraint is expressed by

$$
n \dot{k}=n y-E-G-n c
$$

where $c$ denotes consumption per capita.

\subsection{Welfare}

The agent's lifetime utility is represented by the intertemporal isoelastic utility function that depends only on consumption

$$
W \equiv \int_{0}^{\infty} \frac{c^{1-\sigma}}{1-\sigma} e^{-\rho t} d t, \quad \rho>0, \quad \sigma>0
$$

where $1 / \sigma$ denotes the intertemporal elasticity of substitution and $\rho$ is the agent's rate of time preference.

\section{Central planner}

As a benchmark, we begin by considering a centrally planned economy in which the decision maker can choose the resource allocation directly. To sustain an equilibrium of ongoing growth, both types of government expenditures must be tied to the scale of economy. This can be achieved most conveniently by assuming that the government sets its expenditures for $E$ and $G$ as fixed fractions of aggregate output, $Y \equiv n y$, namely

$$
\begin{array}{ll}
E=e Y & 0<e<1 \\
G=g Y & 0<g<1
\end{array}
$$

An expansion in government expenditure is parameterized by increases in the expenditure shares, $e$ 
and $g$. We analyze the case in which the government acts as a benevolent social planner, that determines consumption, the rate of capital accumulation, and both public inputs, to maximize the intertemporal utility function of the representative agent, (5), subject to the capital accumulation equation, (4). The social planner is aware of any possible congestion effects, thus internalizing the link between individual and aggregate capital, $K=n k$. Using this relationship, the congestion functions (2) become $E_{S}=E n^{-\varepsilon_{E}}$ and $G_{S}=G n^{-\varepsilon_{G}}$, and together with equations (2) and (6), the production function (1) can be rewritten as

$$
y=F\left(k, E n^{-\varepsilon_{E}}, G n^{-\varepsilon_{G}}\right)=F\left(k, \operatorname{eyn}^{-\varepsilon_{E}}, g y n^{-\varepsilon_{G}}\right)
$$

As a consequence of the homogeneity assumption, the equilibrium individual production function as perceived by the central planner turns out to be linear in capital and thus, for appropriate preferences, can sustain an equilibrium of ongoing growth. ${ }^{8}$ The equilibrium production function is given by

$$
y=\phi\left(e n^{-\varepsilon_{E}}, g n^{-\varepsilon_{G}}\right) k \quad \phi_{1}>0, \phi_{2}>0
$$

where $\phi$, which reflects both the marginal and average productivity of capital, is an increasing function of both public inputs.

The social planner's optimization can be most conveniently conducted in two stages. First, we determine the equilibrium in which $e$ and $g$ are set arbitrarily, while in the second stage $e$ and $g$ are set optimally, along with individual consumption and capital accumulation. This two-stage approach has the advantage in that it enhances our understanding of the optimal tax rates and user fees, which depend both on the socially optimal level of the government expenditure together with the deviation of the actual expenditure from its social optimum.

\subsection{Arbitrarily set fractions of $e$ and $g$}

If the planner sets the expenditure parameters $e$ and $g$ arbitrarily, the optimization problem is simply to maximize welfare (5) subject to the resource constraint

\footnotetext{
${ }^{8}$ The relationship between the basic production function (1) and the "AK form" as set out in (8) is discussed in the Appendix.
} 


$$
\dot{k}=(1-e-g) y-c
$$

where $y$ is given by equation (8). Optimizing over consumption, $c$, and capital, $k$ leads to the standard optimality conditions

$$
\begin{gathered}
c^{-\sigma}=\lambda \\
(1-e-g) \frac{\partial y}{\partial k}=\rho-\frac{\dot{\lambda}}{\lambda}
\end{gathered}
$$

where $\lambda$ denotes the shadow price of capital. Equation (9a) equates marginal utility to the shadow value of an additional unit of capital, $\lambda$, while equation (9b) equates the social rate of return on capital to the rate of return on consumption. Combining (9a) and (9b) the equilibrium growth rate is given by ${ }^{9}$

$$
\tilde{\varphi}=\frac{1}{\sigma}\left[(1-e-g) \phi\left(e n^{1-\varepsilon_{E}}, g n^{1-\varepsilon_{G}}\right)-\rho\right]
$$

Differentiating (10) with respect to $e$ and $g$, respectively, we obtain

$$
\begin{aligned}
& \frac{\partial \tilde{\varphi}}{\partial e}=\frac{1}{\sigma e} \frac{y}{k \eta_{k}}\left[(1-g) \eta_{E}-e\left(1-\eta_{G}\right)\right] \\
& \frac{\partial \tilde{\varphi}}{\partial g}=\frac{1}{\sigma g} \frac{y}{k \eta_{k}}\left[(1-e) \eta_{G}-g\left(1-\eta_{E}\right)\right]
\end{aligned}
$$

where $\eta_{k}, \eta_{E}, \eta_{G}$ are the elasticities of output as specified by (1) with respect to the three productive factors, $k, E, G$, respectively. Thus, we may write:

$$
\begin{aligned}
& \operatorname{sgn}\left(\frac{\partial \tilde{\varphi}}{\partial e}\right)=\operatorname{sgn}\left(\frac{\eta_{E}}{1-\eta_{G}}-\frac{e}{1-g}\right)=\operatorname{sgn}\left(\frac{\eta_{e}}{1+\eta_{e}}-\frac{e}{1-g}\right) \\
& \operatorname{sgn}\left(\frac{\partial \tilde{\varphi}}{\partial g}\right)=\operatorname{sgn}\left(\frac{\eta_{G}}{1-\eta_{E}}-\frac{g}{1-e}\right)=\operatorname{sgn}\left(\frac{\eta_{g}}{1+\eta_{g}}-\frac{g}{1-e}\right)
\end{aligned}
$$

where $\eta_{e}, \eta_{g}$ are the elasticities of output with respect to the shares of the two forms of public input,

\footnotetext{
${ }^{9}$ The derivation of (10) is straightforward. Taking the time derivative of (9a,) combining with (9b), and recalling (8), immediately yields the equilibrium growth rate of consumption. Assuming the balanced growth path along which consumption and capital grow at the same rate, (4') yields the consumption-capital ratio consistent with this assumption.
} 
e, g, respectively. ${ }^{10}$ Setting equations (11) to zero, we see that the growth-maximizing shares of the two types of public input are given by

$$
\begin{gathered}
e^{*}=\eta_{E}=\frac{\eta_{e}}{1+\eta_{e}+\eta_{g}} \\
g^{*}=\eta_{G}=\frac{\eta_{g}}{1+\eta_{e}+\eta_{g}}
\end{gathered}
$$

Thus increasing either form of government expenditure will increase the growth rate until its share of output equals its corresponding productive elasticity. It is important to emphasize that except for the Cobb-Douglas production function, these production elasticities are not constant but vary with the public inputs, $E$ and $G$, as well as with other parameters. ${ }^{11}$ This relationship will become apparent in our treatment of the CES production function in Section 7.

\subsection{Optimally set fractions of $e$ and $g$}

It is straightforward to show that when $e$ and $g$ are optimally chosen leads to two further optimality conditions that can be conveniently summarized by

$$
\begin{aligned}
& \operatorname{sgn}\left(\frac{\partial W}{\partial e}\right)==\operatorname{sgn}\left((1-e-g) \eta_{e}-e\right)=\operatorname{sgn}\left(\frac{\eta_{e}}{1+\eta_{e}}-\frac{e}{1-g}\right)=\operatorname{sgn}\left(\frac{\partial \tilde{\varphi}}{\partial e}\right) \\
& \operatorname{sgn}\left(\frac{\partial W}{\partial g}\right)==\operatorname{sgn}\left((1-e-g) \eta_{g}-g\right)=\operatorname{sgn}\left(\frac{\eta_{g}}{1+\eta_{g}}-\frac{g}{1-e}\right)=\operatorname{sgn}\left(\frac{\partial \tilde{\varphi}}{\partial g}\right)
\end{aligned}
$$

from which we infer that for either form of public input, its qualitative impact on the welfare of the representative agent is identical to its qualitative effect on the growth rate. It immediately follows from (12)-(14) that the growth-maximizing expenditure shares given in (13) are also welfaremaximizing. The equilibrium optimal growth rate is thus given by

$$
\varphi^{*}=\frac{1}{\sigma}\left[\left(1-e^{*}-g^{*}\right) \phi\left(e^{*} n^{1-\varepsilon_{E}}, g^{*} n^{1-\varepsilon_{G}}\right)-\rho\right]
$$

\footnotetext{
${ }^{10}$ The relationships between the two sets of elasticities are found in the Appendix.

${ }^{11}$ This means that solving explicitly for the optimal government expenditure shares may involve solving a highly nonlinear pair of equations that may or may not yield closed-form solutions.
} 


$$
=\frac{1}{\sigma}\left[\left(1-\eta_{E}^{*}-\eta_{G}^{*}\right) \phi\left(\eta_{E}^{*} n^{1-\varepsilon_{E}}, \eta_{G}^{*} n^{1-\varepsilon_{G}}\right)-\rho\right]
$$

where $e^{*}, g^{*}$ are the growth and welfare-maximizing expenditure shares, as given in (13), and $\eta_{E}^{*}, \eta_{G}^{*}$ are the corresponding production elasticities, evaluated at the optimum. We thus conclude that the well known Barro (1990) proposition pertaining to the coincidence of growth and welfare maximizing government expenditures extends to both types of public input, and indeed extends beyond the Cobb-Douglas production function to the quite general specification adopted in (1). ${ }^{12}$

\section{Equilibrium in the decentralized economy}

We turn now to the representative agent in the decentralized economy. The individual's production function is given by equation (1). As noted, the individual has to pay an income tax, $\tau$, a lump-sum tax, $l$, as well as the user fee, $q$, if he uses the excludable part of the government input. For the present we abstract from the monopolistic pricing of the excludable public input, delaying our discussion of this aspect until Section 7. Both public inputs are subject to relative congestion as represented by equation (2). In contrast to the social planner, the individual does not realize the negative external effect of capital accumulation. Thus, given the homogeneity, the production function as perceived by the individual is given by

$$
y=F\left(k, E\left(\frac{k}{K}\right)^{\varepsilon_{E}}, G\left(\frac{k}{K}\right)^{\varepsilon_{G}}\right)=\phi\left(\frac{E}{k}\left(\frac{k}{K}\right)^{\varepsilon_{E}}, \frac{G}{k}\left(\frac{k}{K}\right)^{\varepsilon_{G}}\right) k
$$

The individual's optimization problem is to choose the time paths for individual consumption, capital accumulation, and his use of the excludable public input to maximize utility as given by equation (5) subject to the rate of capital accumulation

$$
\dot{k}=(1-\tau) y-c-q E-l
$$

and output $y$ as given by (16). The new feature is the appearance of the user fee in the agent's budget constraint (17). The optimality conditions are

\footnotetext{
${ }^{12}$ However, its robustness should not be overstated. Turnovsky (2000) discusses a number of important circumstances in which it ceases to hold. These include: (i) the introduction of risky technology, (ii) the government input as a stock rather than as a flow, (iii) adjustment costs associated with investment.
} 


$$
\begin{gathered}
c^{-\sigma}=\lambda \\
(1-\tau) \frac{\partial y}{\partial k}=\rho-\frac{\dot{\lambda}}{\lambda} \\
(1-\tau) \frac{\partial y}{\partial E}=q
\end{gathered}
$$

Equation (18a) coincides with (9a) for the social planner, while equation (18b) now equates the after tax marginal product of private capital to the rate of return on consumption. The equilibrium marginal product of private capital derived from equation (16) is given by ${ }^{13}$

$$
\frac{\partial y}{\partial k}=\phi(.)\left(1-\left(1-\varepsilon_{E}\right) \eta_{E}-\left(1-\varepsilon_{G}\right) \eta_{G}\right)
$$

Since individuals ignore the consequences of their own activities on the aggregate economy the individually perceived marginal product of capital includes an externality. Agents overestimate the resulting marginal product if the public input is congested, that is if $\varepsilon_{E}>0$ and/or $\varepsilon_{G}>0$. Equation (18c) is the formal statement of exclusion. As individuals have to pay directly for the use of the excludable public input, $E$, they determine their optimal usage by equating its net marginal product to its marginal cost, $q$, (the user fee).

We assume that the government sets the user fee to ensure that the demand for the excludable public good, chosen by the private sector, coincides with its supply set by the government. Using the relationship $E=$ eny, the market equilibrium in the decentralized economy is thus formally represented by the following two equations

$$
\begin{aligned}
& \varphi=\frac{1}{\sigma}\left[(1-\tau) \phi(.)\left(1-\left(1-\varepsilon_{E}\right) \eta_{E}-\left(1-\varepsilon_{G}\right) \eta_{G}-\rho\right]\right. \\
& (1-\tau) \eta_{E}=\text { qne }
\end{aligned}
$$

Given the expenditure shares $e, g$, these two equations jointly determine the equilibrium growth rate and the market-clearing user fee. Indeed, the latter equation can be interpreted as being a marketclearing condition for the excludable public input.

\footnotetext{
${ }^{13}$ See Appendix for the derivation of this equation.
} 


\section{General characterization of optimal tax and user cost}

We now analyze the consequences of fiscal policy on the market equilibrium and discuss its welfare consequences. From a welfare point of view any fiscal policy should allow for the provision of the optimal quantities of $E$ and $G$, and internalize, if necessary, any negative external effect of excess capital accumulation. We assume that the budget balances in each period. Thus we assume that the user fee is determined to equate the marginal cost and marginal revenue of the excludable input. We begin with the analysis for optimally set expenditure shares and then turn to the case where the government sets $e$ and $g$ non-optimally, but consistent with private demand.

\subsection{Government sets e and g optimally}

In this case the expenditure shares are determined in accordance with equations (13), that is, $e^{*}=\eta_{E}$ and $g^{*}=\eta_{G}$. Thus the market clearing condition in (19b) simplifies to

$$
1-\tau=q n
$$

Equating the equilibrium growth rate (19a) to the optimal growth rate (15), and using the relation (20) yields the optimal income tax rate and user fee as functions of the optimally set government expenditure shares (or equivalently the corresponding partial production elasticities, where * identifies the optimum) and the congestion parameters

$$
\begin{aligned}
\tau^{*} & =\frac{\varepsilon_{E} e^{*}+\varepsilon_{G} g^{*}}{1-\left(1-\varepsilon_{E}\right) e^{*}-\left(1-\varepsilon_{G}\right) g^{*}}=\frac{\varepsilon_{E} \eta_{E}^{*}+\varepsilon_{G} \eta_{G}^{*}}{1-\left(1-\varepsilon_{E}\right) \eta_{E}^{*}-\left(1-\varepsilon_{G}\right) \eta_{G}^{*}} \\
q^{*} & =\frac{1}{n} \frac{1-e^{*}-g^{*}}{1-\left(1-\varepsilon_{E}\right) e^{*}-\left(1-\varepsilon_{G}\right) g^{*}}=\frac{1}{n} \frac{1-\eta_{E}^{*}-\eta_{G}^{*}}{1-\left(1-\varepsilon_{E}\right) \eta_{E}^{*}-\left(1-\varepsilon_{G}\right) \eta_{G}^{*}}
\end{aligned}
$$

Note again that, except in the case of the Cobb-Douglas production function, $e^{*}=\eta_{E}^{*}, g^{*}=\eta_{G}^{*}$ vary with the quantities of the public inputs used, as well as with the congestion parameters. ${ }^{14}$ The presence of congestion associated with either input causes individuals to overestimate the social marginal product of capital, generating an incentive to over-accumulate private capital. The

\footnotetext{
${ }^{14}$ We shall illustrate this aspect in the context of the CES production function in Section 8, below.
} 
resulting growth rate in the decentralized economy becomes sub-optimally high. Hence, a positive tax on income is required in order to reduce the incentive to accumulate capital, and thus correct for this externality. At the same time, the income tax reduces the after-tax marginal product of the excludable public input, $E$. As the individual demand for $E$ requires equating the (after-tax) marginal product of $E$ to its marginal cost, an increase in $\tau$ reduces the marginal product, thus reducing individual demand. In order to ensure that demand for the excludable good is maintained equal to the optimally set supply, the government decreases the user fee as consequence of an increase in $\tau$. We may summarize this with:

Proposition 1: $\quad$ Assume that the government sets the expenditure shares of the excludable and non-excludable public goods optimally. The optimal income tax and the optimal user fees are functions of the partial production elasticities of the inputs, together with their respective congestions. The existence of congestion in either good raises the income tax and reduces the user fee.

The result that congestion favors an income tax is consistent with Barro and Sala-i-Martin's (1992) conclusion, although in their model they interpret the income tax as an approximation to a user fee and note its superiority over lump-sum taxation. In our case the comparison is between the income tax and an explicit user fee.

The mechanism described above, according to which the income tax internalizes the congestion, has one counter-intuitive implication, namely that congestion in the non-excludable public good reduces the equilibrium user fee for the excludable good. Intuitively, one might have expected that congestion in the non-excludable good would raise the demand for the excludable input, thereby raising its user fee. On the other hand, the fact that congestion in the excludable good, by reducing the marginal product of that input, reduces the user fee is quite intuitive.

\subsection{Government sets $g$ and e arbitrarily, but the latter consistent with private demand}

Studying this case brings out the relationship between the financing instruments, on the one hand, and the deviations of the actual expenditure shares from their respective optima, on the other. 
We consider the second-best growth rate of the centrally planned economy, as determined in equation (10) as a reference. To replicate this second best optimum, we require

$$
\begin{aligned}
& 1-e-g=(1-\tau)\left(1-\left(1-\varepsilon_{E}\right) \eta_{E}-\left(1-\varepsilon_{G}\right) \eta_{G}\right) \\
& (1-\tau) \eta_{E}=\text { qne }
\end{aligned}
$$

The corresponding income tax rate and user fee are now given by

$$
\begin{gathered}
\hat{\tau}=\frac{e-\left(1-\varepsilon_{E}\right) \eta_{E}+g-\left(1-\varepsilon_{G}\right) \eta_{G}}{1-\left(1-\varepsilon_{E}\right) \eta_{E}-\left(1-\varepsilon_{G}\right) \eta_{G}} \\
\hat{q}=\left(\frac{1}{n e}\right) \frac{\eta_{E}(1-e-g)}{1-\left(1-\varepsilon_{E}\right) \eta_{E}-\left(1-\varepsilon_{G}\right) \eta_{G}}
\end{gathered}
$$

In this case the second-best optimal tax and user fee depend upon actual expenditure shares as well as the production elasticities and congestion parameters. There are now two externalities that need to be corrected: (i) the degree of congestion, and (ii) the deviations in the actual expenditures, $e$ and $g$ from their respective optima. Because of the fact that the productive elasticities are functions of the actual and optimal expenditure shares, the comparison of $\hat{\tau}, \hat{q}$ with the first-best optimal values, $\tau^{*}, q^{*}$ is not in general practical, although it becomes feasible in the case of the CES production function, discussed in Section 8, below.

One comparison of some interest is that

$$
\begin{aligned}
& \frac{\partial \hat{\tau}}{\partial \eta_{I}}<0, \quad \frac{\partial \hat{q}}{\partial \eta_{I}}>0, \quad I=E, G \\
& \frac{\partial \tau^{*}}{\partial \eta_{I}} \geq 0, \quad \frac{\partial q^{*}}{\partial \eta_{I}} \leq 0, \quad I=E, G
\end{aligned}
$$

Holding the fraction of government expenditures fixed, an increase in the productivity of either public input (as measured by the productive elasticities, $\eta_{E}, \eta_{G}$ ) raises output and the tax base. This permits the second-best tax rate to be reduced, while the higher productivity yielding enhanced productive benefits, allows a higher user fee to be charged. But since the higher productive elasticity induces more usage of either input, thereby reducing its marginal productivity this in general raises 
the first-best tax rate and reduces the optimal usage fee. The exception is the polar case where both inputs are pure public goods, in which case (21) implies $\tau^{*}=0, q^{*}=1 / n$, independent of the productive elasticities.

\section{Optimally Set Expenditure Shares: Budgetary Implications}

It is evident that the degrees of congestion associated with the two types of public input have important consequences for their mode of financing and therefore for government budget balance. To focus on this important issue we assume that the government sets both expenditure ratios at their respective optima, namely $e^{*}=\eta_{E}$, and $g^{*}=\eta_{G}$, in accordance with (13). To sustain this equilibrium, the revenue-generating fiscal instruments must satisfy (21). The issue we want to address is the extent to which each type of public good can be individually financed entirely from its designated source of revenue - the non-excludable input from tax revenues, the excludable input from the user fee - as well as the extent to which aggregate expenditure on the two public goods can be financed out of both revenue sources, taken together.

Given $n$ agents, total revenues earned from these two sources equal $n \tau y+n q E$ and we are concerned with the extent to which this is compatible with total public expenditure $G+E$. Recalling the expenditure rules, (6a), (6b), and with expenditure shares set optimally, the government can balance its budget using these two instruments alone (i.e. without lump-sum tax financing) if and only if

$$
\tau+n q e^{*}=e^{*}+g^{*}
$$

As we shall see, the extent to which this is possible depends crucially upon the degrees of congestion and the optimal fiscal policy they induce.

To address this issue, it is convenient to rewrite (21a) and (21b) in the form

$$
\begin{aligned}
& \tau^{*}=g^{*}+\frac{\varepsilon_{E} e^{*}-g^{*}\left[\left(1-\varepsilon_{G}\right)\left(1-g^{*}\right)-\left(1-\varepsilon_{E}\right) e^{*}\right]}{1-\left(1-\varepsilon_{E}\right) e^{*}-\left(1-\varepsilon_{G}\right) g^{*}} \\
& n q^{*} e^{*}=e^{*}-\frac{\left(\varepsilon_{E} e^{*}+\varepsilon_{G} g^{*}\right) e^{*}}{1-\left(1-\varepsilon_{E}\right) e^{*}-\left(1-\varepsilon_{G}\right) g^{*}}
\end{aligned}
$$


and thus

$$
\tau^{*}+q^{*} n e^{*}=g^{*}+e^{*}+\frac{\left(1-g^{*}-e^{*}\right)\left[\varepsilon_{E} e^{*}-\left(1-\varepsilon_{G}\right) g^{*}\right]}{1-\left(1-\varepsilon_{E}\right) e^{*}-\left(1-\varepsilon_{G}\right) g^{*}}
$$

These expressions highlight how the relationship between revenues and expenditures depends upon the degree of congestion. From these equations we can derive the following

Proposition 2: $\quad$ (i) The revenue generated by the user fee suffices to finance the excludable public input if and only if the optimal tax rate is zero. This occurs if and only if neither public input is subject to congestion.

(ii) The total revenue generated suffices to finance total public expenditure if and only if the optimal ratios of the two inputs satisfies $e^{*} / g^{*}=\left(\left(1-\varepsilon_{G}\right) / \varepsilon_{E}\right)$. In the case that congestion is uniform across the two inputs, $\varepsilon_{E}=\varepsilon_{G}=\varepsilon$, the government budget (25) will balance if and only if $\varepsilon=g^{*} /\left(e^{*}+g^{*}\right)$, i.e. if and only if the degree of congestion equals the fraction of non-excludable in total public expenditure.

Further insight is obtained by discussing special cases and the following will be considered.

(i) $\varepsilon_{E}=\varepsilon_{G}=0: \quad$ In case of absence of congestion in either public input, as noted, the optimal fiscal policy (21a) and (21b) reduces to

$$
\begin{aligned}
\tau^{*} & =0 \\
q^{*} & =\frac{1}{n}
\end{aligned}
$$

With a zero income tax rate, the after-tax marginal product of $E$ is not distorted and the optimal user fee equals the marginal cost of providing $E$. Substituting these optimal tax rates in (25) we see that while the expenditure of the excludable good is self-financing (consistent with Proposition 3), the expenditure on the non-excludable good is not. The provision of these optimally supplied public goods is sustainable only as long as the government has at its disposal (positive) lump-sum taxation, that may be employed to finance the non-excludable good. 
(ii) $\varepsilon_{E}=\varepsilon_{G}=1$ : Suppose that both public inputs are proportionally congested. In this case, optimal fiscal policy, (21a) and (21b), becomes

$$
\begin{aligned}
& \tau^{*}=e^{*}+g^{*}>g^{*} \\
& q^{*}=\frac{1}{n}\left(1-e^{*}-g^{*}\right)<\frac{1}{n}
\end{aligned}
$$

The striking aspect of this result is that tax revenues alone suffice to finance the entire production of the optimally provided public inputs. Thus, although we introduce excludability, it is the income tax that internalizes the external effect for both parts of the public input, reducing the incentive that would otherwise exist to over-accumulate capital. In addition, the government receives positive user fee revenues (that would, however, be insufficient to finance the entire amount of $E$ ). These revenues are the consequence of the individual demand for $E$ as described in (22b). The positive income tax rate reduces the after-tax marginal product of $E$. If $e$ is set optimally the market clearing condition of $E$ requires a user fee that is below the optimal level, but still positive. Thus, since total revenues generated exceed the expenditure required, the excess revenues should be rebated via a growth-neutral fiscal instrument, such as a (negative) lump-sum tax.

(iii) $\varepsilon_{E}=0, \varepsilon_{G}=1$ : We now assume that the excludable part is not congested, whereas the nonexcludable part of the public production input is proportionally congested. The optimal tax rate and user fee satisfy

$$
\begin{aligned}
& e^{*}+g^{*}>\tau^{*}=\frac{g^{*}}{1-e^{*}}>g^{*}>0 \\
& q^{*}=\left(\frac{1}{n}\right) \frac{1-e^{*}-g^{*}}{1-e^{*}}<\frac{1}{n}
\end{aligned}
$$

Substituting these expressions into (25) implies further

$$
\tau^{*}+n q^{*} e^{*}=e^{*}+g^{*}
$$

While the revenue generated by the user fee is insufficient to finance the excludable part of the 
public input, $E$, the income tax revenue exceeds the amount necessary to finance the non-excludable component, $G$. Indeed, the excess tax revenues generated equal precisely the amount necessary to make up the shortfall to finance fully the excludable public input. Thus with tax revenues in part subsidizing the excludable input, the government can balance its budget without needing to introduce an additional fiscal instrument.

(iv) $\varepsilon_{E}=1, \varepsilon_{G}=0$ : Finally, we assume that the excludable part of the public production input is proportionally congested, while the non-excludable part is a pure public good. The optimal tax rate and fee then are given by

$$
\begin{aligned}
& \tau^{*}=\frac{e^{*}}{1-g^{*}}=g^{*}+\frac{e^{*}-g^{*}\left(1-g^{*}\right)}{1-g^{*}}>g^{*} \\
& q^{*}=\left(\frac{1}{n}\right) \frac{1-e^{*}-g^{*}}{1-g^{*}}<\frac{1}{n}
\end{aligned}
$$

which implies that

$$
\tau^{*}+n q^{*} e^{*}=e^{*}+g^{*}+\frac{e^{*}\left(1-e^{*}\right)-g^{*}\left(1-g^{*}\right)}{1-g^{*}}
$$

Again, the revenues from the user fee are insufficient to financethe optimal amount of the excludable good. But now, excess tax revenues may or may not arise. Several cases need to be distinguished. First, if $e^{*}=g^{*}\left(1-g^{*}\right)$, then the tax revenues are sufficient to provide exactly the efficient amount of the non-excludable good, $G$. If $e^{*}<g^{*}\left(1-g^{*}\right)$, tax revenues are insufficient to finance even the non--excludable part of the public input. In both these cases there is an overall budgetary shortfall. Only if $e^{*}>g^{*}\left(1-g^{*}\right)$ does the government generate sufficient tax revenues to finance the the nonexcludable good. In this case, there will still be an overall budgetary shortfall as long as $g^{*}\left(1-g^{*}\right)>e^{*}\left(1-e^{*}\right)$. The total budget will be exactly balanced without an additional instrument if and only if $e^{*}=g^{*}$. If $\left(1-g^{*}\right)>e^{*}>g^{*}$ excess total revenues are generated, leaving resources available that can be redistributed back to the agents via a lump-sum rebate.

These results highlight how the equilibrium user fee declines with the degree of congestion in the excludable input. This is a consequence of the assumed exogeneity of congestion, and because 
the individual demand for $E$ requires the marginal revenue and marginal cost of $E$ to be equalized. As the two fiscal instruments, $\tau$ and $q$ are linked together [see equation (22b)], it is the income tax rate that internalizes the external effects of capital utilization. Thus, the optimal income tax rate is positive if either public good is subject to congestion, reducing the after-tax marginal product of $E$. Thus $q^{*}$ must be reduced below marginal cost for the market clearing condition (22b) to be met.

We may summarize these special cases as follows:

Proposition 3: $\quad$ (i) If $\varepsilon_{E}=\varepsilon_{G}=0$ the expenditure of the excludable input is financed entirely by the optimal user fee, whereas the non-excludable part must be financed via a growth neutral instrument.

(ii) If $\varepsilon_{E}=\varepsilon_{G}=1$ the optimal income tax and user fee yield excess revenues that can be rebated in a growth neutral manner.

(iii) If $\varepsilon_{E}=0, \varepsilon_{G}=1$ the government budget (25) is balanced. The excess tax revenue exactly covers the shortfall generated by the fee revenue.

(iv) If $\varepsilon_{E}=1, \varepsilon_{G}=0$, whether the income tax revenues suffice to finance the revenue shortfall associated with the user fee depends upon the relative sizes of the optimal expenditure shares.

\section{Monopoly Pricing}

Thus far we have assumed that the government provides the excludable part of infrastructure at a price equal to its marginal costs. But as the government is the unique supplier of the public production inputs it is reasonable to analyze the consequences of its acting as a monopolist. It then determines the user fee following the rule of equating marginal cost and marginal revenue. The user fee is then a function of the excludable input, $q(E)$, and the marginal revenue from providing $E$ is

$$
\frac{\partial q(E)}{\partial E} E+q(E)=q\left(1+\frac{1}{\delta_{E, q}}\right)
$$


where $\delta_{E, q}$ denotes the price elasticity of demand for $E$ and is equal to the negative reciprocal value of the degree of monopoly power, denoted by $\omega$. Together with equation (22b), market clearance in the provision of $E$ now requires

$$
(1-\tau) \eta_{E}=n q(1-\omega) e
$$

This relation, together with the growth rate given in equation (22a), describes the market equilibrium within the monopolistic setting. Again, we analyze the optimal fiscal policy for the optimally set expenditure shares, $e^{*}$ and $g^{*}$. The first-best growth rate in equation (15) again serves as the reference point. It turns out that the optimal income tax rate is not affected by the monopoly and coincides with that given in (21a). In contrast, the optimal user fee is directly influenced by monopolistic behavior. It is derived analogously to (21b) and is given by

$$
q^{*}=\left(\frac{1}{(1-\omega) n}\right) \frac{\left(1-e^{*}-g^{*}\right)}{\left[1-\left(1-\varepsilon_{E}\right) e^{*}-\left(1-\varepsilon_{G}\right) g^{*}\right]}=\left(\frac{1}{(1-\omega) n}\right) \frac{1-\eta_{E}^{*}-\eta_{G}^{*}}{1-\left(1-\varepsilon_{E}\right) \eta_{E}^{*}-\left(1-\varepsilon_{G}\right) \eta_{G}^{*}}
$$

The optimal user fee increases with an increase in the degree of monopoly and exceeds $q^{*}$, as determined in (21b). Analogous to (26), we may express the optimal fiscal policy in the form

$$
\begin{aligned}
& \tau^{*}=g^{*}+\frac{\varepsilon_{E} e^{*}-g^{*}\left[\left(1-\varepsilon_{G}\right)\left(1-g^{*}\right)-\left(1-\varepsilon_{E}\right) e^{*}\right]}{1-\left(1-\varepsilon_{E}\right) e^{*}-\left(1-\varepsilon_{G}\right) g^{*}} \\
& n q^{*} e^{*}=e^{*}+\frac{\omega\left(1-e^{*}-g^{*}\right)-(1-\omega)\left(\varepsilon_{E} e^{*}+\varepsilon_{G} g^{*}\right)}{(1-\omega)\left[1-\left(1-\varepsilon_{E}\right) e^{*}-\left(1-\varepsilon_{G}\right) g^{*}\right]} e^{*}
\end{aligned}
$$

and thus

$$
\tau^{*}+q^{*} n e^{*}=g^{*}+e^{*}+\frac{\left(1-g^{*}-e^{*}\right)\left[(1-\omega)\left[\varepsilon_{E} e^{*}-\left(1-\varepsilon_{G}\right) g^{*}\right]+\omega e^{*}\right]}{(1-\omega)\left[1-\left(1-\varepsilon_{E}\right) e^{*}-\left(1-\varepsilon_{G}\right) g^{*}\right]}
$$

Despite not affecting the optimal tax, the presence of monopoly power still plays an important role in the overall structure of optimal fiscal policy. Most significantly, we see that the user fee can now generate more revenue than is required to fully finance the excludable public input. Recalling (21b), (26b’) implies 


$$
q^{*} \frac{1}{<} \frac{1}{n} \text { according to whether } \omega \frac{>}{<} \tau^{*}
$$

Likewise, it is apparent from (26') that as $\omega$ increases, total revenues suffice to cover total expenditure.

Further intuition into the role of the monopolistic pricing is obtained by briefly considering special cases. Since the optimal tax rate is unaffected, we shall focus primarily on the user cost.

(i) $\varepsilon_{E}=\varepsilon_{G}=0:$ In this case, (27b) is modified to

$$
q^{*}=\frac{1}{n(1-\omega)}>\frac{1}{n}
$$

With $\omega>0=\tau^{*}$, there are no income tax revenues but the user fee revenues exceed the expenditure necessary to finance the optimal amount of $E$. Whether or not these revenues suffice to finance the entire expenditure without an additional instrument depends on the degree of monopoly: If $\omega=g^{*} /\left(e^{*}+g^{*}\right)$, the fee revenues exactly suffice to provide the optimal amounts of both public inputs. If the degree of monopoly is higher there are excess revenues and if the degree of monopoly is lower the excess fee revenues suffice to finance only a part of the non-excludable input. In the last two cases a growth neutral instrument is needed to close the budget in each period.

(ii) $\varepsilon_{E}=\varepsilon_{G}=1$ : The optimal fiscal user cost becomes

$$
q^{*}=\frac{1-e^{*}-g^{*}}{n(1-\omega)}>\frac{1}{n} \text { according as } \omega \frac{>}{<} \tau^{*}=e^{*}+g^{*}
$$

The fee revenues may or may not suffice to finance the provision of the excludable part of infrastructure, depending on the degree of monopoly. Howewer, since the tax revenues alone suffice to finance total expenditure, total revenues exceed requirements and the excess revenues should be redistributed via a (negative) lump-sum tax.

(iii) $\varepsilon_{E}=0, \varepsilon_{G}=1$ : In this case the optimal user fee satisfies

$$
q^{*}=\frac{1-e^{*}-g^{*}}{n(1-\omega)\left(1-e^{*}\right)}>\frac{1}{n} \quad \text { according as } \omega \frac{>}{<} \tau^{*}=\frac{g^{*}}{1-e^{*}}
$$


Although the income tax revenues are positive, they do not suffice to provide the entire amount of the non-excludable part of the public input. Depending on the degree of monopoly, the fee revenues may or may not suffice to finance the optimal provision of $E$. The fee revenues are sufficient to provide the optimal amount of $E$ if $\omega=g^{*} /\left(1-e^{*}\right)$, whereas for a lower degree of monopoly the fee revenues are too small. The presence of any monopoly power, $\omega>0$, implies that total revenues exceed total expenditures and a (negative) lump-sum tax will be required to close the budget.

$$
\begin{aligned}
& \varepsilon_{E}=1, \varepsilon_{G}=0: \text { In this final case } \\
& q^{*}=\frac{1}{n(1-\omega)} \frac{1-e^{*}-g^{*}}{1-g^{*}} \geq \frac{1}{n} \quad \text { according as } \omega \stackrel{>}{<} \tau^{*}=\frac{e^{*}}{1-g^{*}}
\end{aligned}
$$

In this case income tax revenues may or may not be sufficient to provide the optimal amount of $G$, and the same is true for the fee revenues and their contribution to the financing of $E$. Whether the entire budget is closed without lump-sum taxing or not depends on $\omega$ and the optimal expenditure shares. Specifically, the budget is closed if and only if $\omega=\left(g^{*}-e^{*}\right) / g^{*}$.

We may summarize the impact of monopoly with

\section{Proposition 4: $\quad$ (i) It is possible for certain degrees of monopoly to realize} excess revenues out of the user fee, something that is not possible if the government provides the excludable part of public input at marginal cost.

(ii) The user fee can fully finance the the provision of the excludable input if $\omega=\tau^{*}$. If the degree of monopoly exceeds (falls short of) the optimal income tax, the financing contribution of the fee exceeds (falls short of) the financing requirement for the excludable input.

(iii) The other financing implications described in Proposition 3 continue to hold.

\section{The CES Production Function}

We now specify the production technology to be a Constant Elasticity of Substitution (CES) production function that is homogeneous of degree one in the three inputs. Specializing the production function in this way not only facilitates the study of optimal fiscal policy, but it is also 
convenient for analyzing the consequences of different degrees of substitution between the inputs for optimal fiscal policy. Thus the production function (1) becomes

$$
y=\left[\alpha k^{-\xi}+\beta G_{S}^{-\xi}+\gamma E_{S}^{-\xi}\right]^{-\frac{1}{\xi}} \quad 0<\alpha<1,0<\beta<1,0<\gamma<1, \alpha+\beta+\gamma=1
$$

where $\theta \equiv 1 /(1+\xi), 0<\theta<\infty$, denotes the elasticity of substitution between the three inputs. Utilizing the congestion function (2), the expenditure shares as given by (6), the equilibrium production function, (7), can be expressed in the linear “AK form”

$$
y=\alpha^{-\frac{1}{\xi}}\left[1-\beta g^{-\xi} n^{-\xi\left(1-\varepsilon_{G}\right)}-\gamma e^{-\xi} n^{-\xi\left(1-\varepsilon_{E}\right)}\right]^{\frac{1}{\xi}} k
$$

\subsection{Centrally planned economy}

As in Section 3, we begin by summarizing the equilibrium growth rate in the centrally planned economy. For arbitrarily set expenditure shares the equilibrium (second-best) growth rate is

$$
\tilde{\varphi}=\frac{1}{\sigma}\left[(1-e-g) \alpha^{-\frac{1}{\xi}}\left(1-\beta g^{-\xi} n^{-\xi\left(1-\varepsilon_{G}\right)}-\gamma e^{-\xi} n^{-\xi\left(1-\varepsilon_{E}\right)}\right)-\rho\right]
$$

Following the procedure employed for the general production function in Section 3, we can verify that the growth-maximizing and welfare-maximizing expenditure shares coincide, being given by

$$
g^{*}=\beta^{\frac{1}{1+\xi}} n^{-\frac{\xi\left(1-\varepsilon_{G}\right)}{1+\xi}} ; e^{*}=\gamma^{\frac{1}{1+\xi}} n^{-\frac{\xi\left(1-\varepsilon_{E}\right)}{1+\xi}}
$$

respectively. In addition, we can compute the production elasticities directly from (1') together with the congestion functions (2) to obtain

$$
\eta_{G}=\beta g^{-\xi} n^{\left(\varepsilon_{G}-1\right) \xi} ; \eta_{E}=\gamma e^{-\xi} n^{\left(\varepsilon_{E}-1\right) \xi}
$$

Combining (32) and (33) yields

$$
\eta_{G}=\left(g^{*}\right)^{1+\xi} g^{-\xi} ; \quad \eta_{E}=\left(e^{*}\right)^{1+\xi} e^{-\xi}
$$

These expressions bring out the point made earlier that in general the production elasticity depends upon the usage of the productive input, as well as the degree of congestion. The exception 
is the Cobb-Douglas production function, $\xi=0$, when $\eta_{G}=\beta, \eta_{E}=\gamma$. Note further from (34) that when $g$ and $e$ are set optimally, this equation implies $\eta_{G}=g^{*}, \eta_{E}=e^{*}$, consistent with (13).

Dividing the two expressions in (32) implies

$$
\left(\frac{g}{e}\right)^{*}=\left(\frac{\beta}{\gamma}\right)^{\frac{1}{1+\xi}} n^{\frac{\xi\left(\varepsilon_{G}-\varepsilon_{E}\right)}{1+\xi}}
$$

from which we see that the optimal ratio of non-excludable to excludable public inputs depends upon (i) their productivity, (ii) the elasticity of substitution, and (iii) their differential degrees of congestion. We may note the following three important cases:

(i) If $\xi \rightarrow \infty$ and thus $\theta=0$ (Leontief production function), then

$$
\left(\frac{g}{e}\right)^{*} \rightarrow n^{\left(\varepsilon_{G}-\varepsilon_{E}\right)}
$$

so that the ratio of their optimal usage depends only upon their differential congestion.

(ii) If $\xi=0$ and thus $\theta=1$ (Cobb-Douglas production function), then

$$
\left(\frac{g}{e}\right)^{*}=\frac{\beta}{\gamma}
$$

so that the ratio of their optimal usage depends only upon their relative productivity and is independent of the degree of congestion,

(iii) If $\xi=-1$ and thus $\theta \rightarrow \infty$ (perfect substitutes)

$$
\left(\frac{g}{e}\right)^{*}= \begin{cases}0 & \text { if } \beta n^{\xi \varepsilon_{G}}<\gamma n^{\xi \varepsilon_{E}} \\ 1 & \text { if } \beta n^{\xi \varepsilon_{G}}=\gamma n^{\xi \varepsilon_{E}} \\ \infty & \text { if } \beta n^{\xi \varepsilon_{G}}>\gamma n^{\xi \varepsilon_{E}}\end{cases}
$$

Thus in the case where the two public inputs are perfect substitutes, the entire public input should take the form of the one having the higher "congestion-adjusted” productivity.

\subsection{Decentralized economy}

Analogous to (16) the representative agent perceives the production function in the form: 


$$
\begin{array}{r}
y=\left[\alpha k^{-\xi}+\beta\left(G\left(\frac{k}{K}\right)^{\varepsilon_{G}}\right)^{-\xi}+\gamma\left(E\left(\frac{k}{K}\right)^{\varepsilon_{E}}\right)^{-\xi}\right]^{-\frac{1}{\xi}} \\
=\left[\alpha+\beta\left(\frac{G}{k}\right)^{-\xi}\left(\frac{k}{K}\right)^{-\xi \varepsilon_{G}}+\gamma\left(\frac{E}{k}\right)^{-\xi}\left(\frac{k}{K}\right)^{-\xi \varepsilon_{E}}\right]^{-\frac{1}{\xi}} k
\end{array}
$$

Taking the derivative of (36) with respect to $k$, in equilibrium the agent's perceived private marginal physical product of capital is

$$
\frac{\partial y}{\partial k}=\frac{y}{k}\left(1-\left(1-\varepsilon_{E}\right) \eta_{E}-\left(1-\varepsilon_{G}\right) \eta_{G}\right)
$$

where $y / k \equiv\left(\eta_{k} / \alpha\right)^{1 / \xi} \equiv \phi($.$) . Omitting for simplicity the monopolistic pricing effect, the market$ equilibrium in the decentralized economy is again given by (19), the only difference being in the specification of the function $y / k \equiv \phi($.$) .$

The second best optimal fiscal policy is again specified by (23). But in light of relationships (34) we can express it in the following intuitive way:

$$
\begin{aligned}
& \hat{\tau}=\frac{g\left[1-\left(1-\varepsilon_{G}\right)\left(g^{*} / g\right)^{1+\xi}\right]+e\left[1-\left(1-\varepsilon_{E}\right)\left(e^{*} / e\right)^{1+\xi}\right]}{1-\left(1-\varepsilon_{G}\right) g\left(g^{*} / g\right)^{1+\xi}-\left(1-\varepsilon_{E}\right) e\left(e^{*} / e\right)^{1+\xi}} \\
& \hat{q}=\left(\frac{1}{n}\right) \frac{\left(e^{*} / e\right)^{1+\xi}(1-e-g)}{1-\left(1-\varepsilon_{G}\right) g\left(g^{*} / g\right)^{1+\xi}-\left(1-\varepsilon_{E}\right) e\left(e^{*} / e\right)^{1+\xi}}
\end{aligned}
$$

Written in this way makes quite explicit how the optimal fiscal policy is correcting for two distortions (i) congestion, and (ii) the deviations of the actual expenditure shares from their respective optima. From (37a) and (37b) we can derive:

Proposition 5: $\quad$ (i) If both $g$ and $e$ are set at their respective optima, $g^{*}, e^{*}$ then $\hat{\tau}=\tau^{*}, \hat{q}=q^{*}$ as given in (21).

(ii) If $g$ is set optimally, then $\hat{\tau}^{>}<\tau^{*}$ and $\hat{q}_{>}^{<} q^{*}$ according to whether $e_{>}^{<} e^{*}$. 
(iii) If $e$ is set optimally, then $\hat{\tau}_{<}^{>} \tau^{*}$ and $\hat{q}_{>}^{<} q^{*}$ according to whether $g_{>}^{<} g^{*}$.

\subsection{Two-Level Production Function}

The elasticity of substitution associated with the production function (1') implies a common mutual degree of substitutability among all three inputs. A natural alternative is to consider a twolevel production function of the form

$$
\begin{aligned}
& y=A k^{\alpha} X^{1-\alpha} \\
& X=\left[\beta G_{S}^{-\xi}+(1-\beta) E_{S}^{-\xi}\right]^{-\frac{1}{\xi}}
\end{aligned}
$$

Where $E_{S}, G_{S}$ continue to be given by (2a) and (2b). In this case the two public inputs combine, with elasticity of substitution $1 /(1+\xi)$ to yield a composite public input, which is then combined with private capital, in accordance with a Cobb-Douglas production function to yield final output. It can be shown that (35) is modified to

$$
\left(\frac{g}{e}\right)^{*}=\left(\frac{\beta}{1-\gamma}\right)^{\frac{1}{1+\xi}} n^{\frac{\xi\left(\varepsilon_{G}-\varepsilon_{E}\right)}{1+\xi}}
$$

so that the comparisons made in (i) - (iii) of 8.1 remain virtually unchanged. Furthermore, the results of Proposition 5 continue to hold. The production structure can obviously be generalized further by replacing (38a) with a CES function, but in this case the comparisons become less straightforward, although easily conducted numerically.

\section{Conclusions}

Many public goods are characterized by two key attributes: rivalry and excludability. While the role of rivalry has been widely considered in the growth literature, excludability has not. In this paper we have introduced both non-excludable and excludable public inputs into a simple endogenous growth model. Our focus has been on deriving the equilibrium growth rate and designing the optimal tax and user-cost tax structure. Our results emphasize the role of congestion 
in determining this optimal structure and the consequences this has in turn for the government's budget. The latter consists of fee and tax revenues that are used to finance the entire public production input and that may or may not suffice to satisfy the financing requirements for the entire input. If no congestion arises, a user fee set at marginal cost yields the optimal amount of the excludable public input while the non-excludable input must be financed via a growth neutral tax. If either form of the public input is congested it is optimal to levy a positive income tax to internalize the external effect. At the same time, due to the interdependence between the optimal fees and income taxes, the optimal user fee is reduced thus decreasing the corresponding fee revenues. Then, the financing contribution of the fees is not sufficient to provide the optimal amount of the excludable input. This result changes if the government passes on user fees at marginal costs but makes use of monopoly pricing that might be accomplished if the government is the unique supplier. It is then possible for certain degrees of monopoly to realize excess revenues out of the user fee that might replace (non-distortionary) taxes in order to finance the entire infrastructure.

We end with two caveats and suggestions for further research on this important topic. First, by introducing government inputs as flows into production, the equilibrium we derive always places the economy on its balanced growth path. This has the analytical advantage of simplifying the characterization of the optimal tax and pricing structure. But much of the recent literature analyzing the role of publicly provided productive inputs recognizes that they should more appropriately be treated as stocks, rather than flows, thereby introducing public as well as private capital. This observation was made early on by Arrow and Kurz (1970) and is also recognized in some of the more contemporary endogenous growth models; see e.g. Futagami, et al. (1993) and Turnovsky (1997). The effect of this is to introduce transitional equilibrium dynamics, suggesting that the optimal financing policies will involve time-varying tax rates and user fees, as the decentralized economy seeks to track the first-best optimal path. ${ }^{15}$

Another limitation of the analysis is that it does not fully capture the linkage between congestion and the user fee. It takes the degree of congestion as given and determines the

\footnotetext{
${ }^{15}$ For example, Turnovsky (1997) shows how the optimal tax rate is time-varying in the case where public capital is nonexcludable.
} 
corresponding equilibrium user fee. As noted at the outset, one of the motivations for imposing a user fee is to reduce congestion, in which case the equilibrium level of congestion would become endogenously determined along with the user fee. To extend the model in this direction would be an important step. 


\section{Appendix}

\section{A.1 Relationship between General Production Function and the Intensive Form}

As the production function

$$
y=F\left(k, E_{S}, G_{S}\right)
$$

is assumed to be homogeneous of degree 1 in its three arguments, $k, E_{S}, G_{S}$, Euler's theorem implies

$$
y=\frac{\partial F}{\partial k} k+\frac{\partial F}{\partial E_{S}} E_{S}+\frac{\partial F}{\partial G_{S}} G_{S} \equiv F_{1} k+F_{2} E_{S}+F_{3} G_{S}
$$

Substituting from the relationships $E_{S}=E n^{1-\varepsilon_{E}}=e n^{1-\varepsilon_{E}} y, G_{S}=G n^{1-\varepsilon_{G}}=g n^{1-\varepsilon_{N}} y$, we can rewrite (A.2) as

$$
\left(1-F_{2} e n^{1-\varepsilon_{E}}-F_{3} g n^{1-\varepsilon_{G}}\right) y=F_{1} k
$$

Now take the total differential of (A.1), to obtain

$$
d y=F_{1} d k+F_{2} d E_{S}+F_{3} d G_{S}
$$

which holding $n, e, g$ constant, implies

$$
\left(1-F_{2} e n^{1-\varepsilon_{E}}-F_{3} g n^{1-\varepsilon_{G}}\right) d y=F_{1} d k
$$

Equations (A.3) and (A.4) imply $d y / y=d k / k$ so that any production function having the above homogeneity properties can be written in the "AK form"

$$
y=\phi\left(e n^{1-\varepsilon_{N}}, g n^{1-\varepsilon_{G}}\right) k
$$

as represented by (8) in the text.

\section{A.2 Relationships between elasticities}

The following relationships between $\eta_{e}, \eta_{g}, \eta_{E}, \eta_{G}$ hold. First, rewriting (A.2) we have 


$$
\frac{\partial F}{\partial k} \frac{k}{y}+\frac{\partial F}{\partial E_{S}} \frac{E_{S}}{y}+\frac{\partial F}{\partial G_{S}} \frac{G_{S}}{y}=1
$$

which in elasticity form can be written as

$$
\eta_{k}+\eta_{E_{S}}+\eta_{G_{S}}=1
$$

Using the fact $E_{S}=E n^{1-\varepsilon_{E}}$ and $G_{S}=G n^{1-\varepsilon_{G}}$

$$
\eta_{E_{S}} \equiv \frac{\partial F}{\partial E_{S}} \frac{E_{S}}{y}=\frac{\partial F}{\partial E} \frac{E_{S}}{n^{1-\varepsilon_{S}} y}=\frac{\partial F}{\partial E} \frac{E}{y} \equiv \eta_{E}
$$

and similarly, $\eta_{G_{S}}=\eta_{G}$, so that (A.7) can be written in the equivalent form

$$
\eta_{k}+\eta_{E}+\eta_{G}=1
$$

To derive the relationships between the elasticities in the aggregate quantities and in the shares, rewrite equation (A.1) as

$$
y=F\left(k, e n^{1-\varepsilon_{E}} y, g n^{1-\varepsilon_{G}} y\right)
$$

Taking derivatives of this with respect to $e, g$, respectively, we obtain

$$
\begin{aligned}
& \frac{\partial y}{\partial e}=\frac{F_{2} n^{1-\varepsilon_{E}} y}{1-F_{2} n^{1-\varepsilon_{E}} e-F_{3} n^{1-\varepsilon_{G}} g}>0 \\
& \frac{\partial y}{\partial g}=\frac{F_{3} n^{1-\varepsilon_{G}} y}{1-F_{2} n^{1-\varepsilon_{E}} e-F_{3} n^{1-\varepsilon_{G}} g}>0
\end{aligned}
$$

Using the above fact that

$$
\eta_{E} \equiv \eta_{E_{S}} \equiv \frac{\partial F}{\partial E_{S}} \frac{E_{S}}{y}=F_{2} e n^{1-\varepsilon_{E}}
$$

and analogously for $\eta_{G}$, (A.10a) and (A.10b) imply

$$
\eta_{e}=\frac{\eta_{E}}{1-\eta_{E}-\eta_{G}}=\frac{\eta_{E}}{\eta_{k}}
$$




$$
\eta_{g}=\frac{\eta_{G}}{1-\eta_{E}-\eta_{G}}=\frac{\eta_{G}}{\eta_{k}}
$$

\section{A.3 Derivation of marginal physical product of capital in decentralized economy}

Differentiating (16) with respect to $k$ yields

$$
\frac{\partial y}{\partial k}=F_{1}+\varepsilon_{E} E F_{2} \frac{k^{\varepsilon_{E}-1}}{K^{\varepsilon_{E}}}+\varepsilon_{G} G F_{3} \frac{k^{\varepsilon_{G}-1}}{K^{\varepsilon_{G}}}
$$

Imposing the equilibrium condition $K=n k$, this simplifies to

$$
\begin{aligned}
& \frac{\partial y}{\partial k}=F_{1}+\varepsilon_{E} F_{2} \frac{E}{k}+\varepsilon_{G} F_{3} \frac{G}{k} \\
& =\frac{y}{k}\left[\frac{F_{1} k}{y}+\varepsilon_{E} F_{2} \frac{E}{y}+\varepsilon_{G} F_{3} \frac{E}{y}\right]
\end{aligned}
$$

Using the above definitions of elasticities, (A.8), and the relationship $y=\phi()$.$k in (8), (A.13)$ immediately yields the expression in the text, namely

$$
\frac{\partial y}{\partial k}=\phi\left(1-\left(1-\varepsilon_{E}\right) \eta_{E}-\left(1-\varepsilon_{G}\right) \eta_{G}\right)
$$




\section{References}

Arrow K. J. and M. Kurz (1970). Public Investment, the Rate of Return, and Optimal Fiscal Policy, John Hopkins University Press, Baltimore.

Barro, R. J. (1990). “Government Spending in a Simple Model of Endogenous Growth,” Journal of Political Economy 98, 103-125.

Barro, R. J. and X. Sala-i-Martin. (1992). “Public Finance in Models of Economic Growth”, Review of Economic Studies 59, 645-661.

Brito, D. L. and W.H. Oakland (1980). “The Monopolistic Provision of Excludable Public Goods,” American Economic Review 70, 691-704.

Bruce, N. and S.J. Turnovsky (1999). "Budget Balance, Welfare, and the Growth Rate: 'Dynamic Scoring' of the Long-run Government Budget,” Journal of Money, Credit, and Banking 31, 162-186.

Cornes, R., and Sandler, T. (1996). The Theory of Externalities, Public Goods, and Club Goods, Cambridge University Press, Cambridge.

Edwards, J. H. Y. (1990). “Congestion Function Specification and the "Publicness” of Local Public Goods,” Journal of Urban Economics 27, 80-96.

Eicher, T. and S.J. Turnovsky (2000). “Scale, Congestion and Growth,” Economica 67, 325-346.

European Commission (2001). White paper: European Transport Policy for 2010: Time to Decide, European Communities, and Luxembourg.

Futagami, K., Y. Morita, andA. Shibata (1993). “Dynamic Analysis of an Endogenous Growth Model with Public Capital,” Scandinavian Journal of Economics 95, 607-625.

Glomm, G. and B. Ravikumar (1994). "Public Investment in Infrastructure in a Simple Growth Model,” Journal of Economic Dynamics and Control 18, 1173-1187.

Ireland, P.N. (1994). "Supply-side Economics and Endogenous Growth,” Journal of Monetary Economics 33, 559-571.

Megginson, W. L. and J.M. Netter (2001). “From State to Market - A Survey of Empirical Studies on Privatization,” Journal of Economic Literature 39, 321-389. 
Ott, I. (2001). “Congestion, Excludability, and Endogenous Growth,” ifo-Studien 47, 453-467.

Rebelo, S. (1991). “Long-run Policy Analysis and Long-run Growth,” Journal of Political Economy 99, 500-521.

Thompson, E.A., (1974), “Taxation and National Defense,” Journal of Political Economy 82, 75582.

Turnovsky, S.J. (1996). “Optimal Tax, Debt, and Expenditure Policies in a Growing Economy,” Journal of Public Economics 60, 21-44.

Turnovsky, S.J. (1997). "Fiscal Policy in a Growing Economy with Public Capital," Macroeconomic Dynamics 1, 615-639.

Turnovsky, S. J. (2000). Methods of Macroeconomic Dynamics, $2^{\text {nd }}$ Ed, MIT Press, Cambridge, MA. Wassmer, R. W. and R.C. Fisher (2002). "Interstate Variation in the Use of Fees to Fund K-12 Public Education,” Economics of Education Revenue, 21, 87-100. 


\title{
CESifo Working Paper Series
}

\author{
(for full list see www.cesifo.de)
}

1362 Christa Hainz, Quality of Institutions, Credit Markets and Bankruptcy, December 2004

1363 Jerome L. Stein, Optimal Debt and Equilibrium Exchange Rates in a Stochastic Environment: an Overview, December 2004

1364 Frank Heinemann, Rosemarie Nagel and Peter Ockenfels, Measuring Strategic Uncertainty in Coordination Games, December 2004

1365 José Luis Moraga-González and Jean-Marie Viaene, Anti-Dumping, Intra-Industry Trade and Quality Reversals, December 2004

1366 Harry Grubert, Tax Credits, Source Rules, Trade and Electronic Commerce: Behavioral Margins and the Design of International Tax Systems, December 2004

1367 Hans-Werner Sinn, EU Enlargement, Migration and the New Constitution, December 2004

1368 Josef Falkinger, Noncooperative Support of Public Norm Enforcement in Large Societies, December 2004

1369 Panu Poutvaara, Public Education in an Integrated Europe: Studying to Migrate and Teaching to Stay?, December 2004

1370 András Simonovits, Designing Benefit Rules for Flexible Retirement with or without Redistribution, December 2004

1371 Antonis Adam, Macroeconomic Effects of Social Security Privatization in a Small Unionized Economy, December 2004

1372 Andrew Hughes Hallett, Post-Thatcher Fiscal Strategies in the U.K.: An Interpretation, December 2004

1373 Hendrik Hakenes and Martin Peitz, Umbrella Branding and the Provision of Quality, December 2004

1374 Sascha O. Becker, Karolina Ekholm, Robert Jäckle and Marc-Andreas Mündler, Location Choice and Employment Decisions: A Comparison of German and Swedish Multinationals, January 2005

1375 Christian Gollier, The Consumption-Based Determinants of the Term Structure of Discount Rates, January 2005

1376 Giovanni Di Bartolomeo, Jacob Engwerda, Joseph Plasmans, Bas van Aarle and Tomasz Michalak, Macroeconomic Stabilization Policies in the EMU: Spillovers, Asymmetries, and Institutions, January 2005 
1377 Luis H. R. Alvarez and Erkki Koskela, Progressive Taxation and Irreversible Investment under Uncertainty, January 2005

1378 Theodore C. Bergstrom and John L. Hartman, Demographics and the Political Sustainability of Pay-as-you-go Social Security, January 2005

1379 Bruno S. Frey and Margit Osterloh, Yes, Managers Should Be Paid Like Bureaucrats, January 2005

1380 Oliver Hülsewig, Eric Mayer and Timo Wollmershäuser, Bank Loan Supply and Monetary Policy Transmission in Germany: An Assessment Based on Matching Impulse Responses, January 2005

1381 Alessandro Balestrino and Umberto Galmarini, On the Redistributive Properties of Presumptive Taxation, January 2005

1382 Christian Gollier, Optimal Illusions and Decisions under Risk, January 2005

1383 Daniel Mejía and Marc St-Pierre, Unequal Opportunities and Human Capital Formation, January 2005

1384 Luis H. R. Alvarez and Erkki Koskela, Optimal Harvesting under Resource Stock and Price Uncertainty, January 2005

1385 Ruslan Lukach, Peter M. Kort and Joseph Plasmans, Optimal R\&D Investment Strategies with Quantity Competition under the Threat of Superior Entry, January 2005

1386 Alfred Greiner, Uwe Koeller and Willi Semmler, Testing Sustainability of German Fiscal Policy. Evidence for the Period 1960 - 2003, January 2005

1387 Gebhard Kirchgässner and Tobias Schulz, Expected Closeness or Mobilisation: Why Do Voters Go to the Polls? Empirical Results for Switzerland, 1981 - 1999, January 2005

1388 Emanuele Bacchiocchi and Alessandro Missale, Managing Debt Stability, January 2005

1389 Assar Lindbeck and Dirk Niepelt, Improving the SGP: Taxes and Delegation rather than Fines, January 2005

1390 James J. Heckman and Dimitriy V. Masterov, Skill Policies for Scotland, January 2005

1391 Emma Galli \& Fabio Padovano, Sustainability and Determinants of Italian Public Deficits before and after Maastricht, January 2005

1392 Angel de la Fuente and Juan Francisco Jimeno, The Private and Fiscal Returns to Schooling and the Effect of Public Policies on Private Incentives to Invest in Education: A General Framework and Some Results for the EU, January 2005

1393 Juan C. Conesa and Carlos Garriga, Optimal Response to a Demographic Shock, January 2005 
1394 Christian Gollier, Optimal Portfolio Management for Individual Pension Plans, February 2005

1395 Ruslan Lukach, Joseph Plasmans and Peter M. Kort, Innovation Strategies in a Competitive Dynamic Setting, February 2005

1396 Gebhard Kirchgässner, (Why) Are Economists Different?, February 2005

1397 Marko Köthenbürger, Panu Poutvaara and Paola Profeta, Why are More Redistributive Social Security Systems Smaller? A Median Voter Approach, February 2005

1398 Gabrielle Demange, Free Choice of Unfunded Systems: A First Assessment, February 2005

1399 Carlos Fonseca Marinheiro, Sustainability of Portuguese Fiscal Policy in Historical Perspective, February 2005

1400 Roel M. W. J. Beetsma and Koen Vermeylen, The Effect of Monetary Unification on Public Debt and its Real Return, February 2005

1401 Frank Asche, Petter Osmundsen and Maria Sandsmark, Is It All Oil?, February 2005

1402 Giacomo Corneo, Media Capture in a Democracy: The Role of Wealth Concentration, February 2005

1403 A. Lans Bovenberg and Thijs Knaap, Ageing, Funded Pensions and the Dutch Economy, February 2005

1404 Thiess Büttner, The Incentive Effect of Fiscal Equalization Transfers on Tax Policy, February 2005

1405 Luisa Fuster, Ayşe İmrohoroğlu and Selahattin İmrohoroğlu, Personal Security Accounts and Mandatory Annuitization in a Dynastic Framework, February 2005

1406 Peter Claeys, Policy Mix and Debt Sustainability: Evidence from Fiscal Policy Rules, February 2005

1407 James M. Malcomson, Supplier Discretion over Provision: Theory and an Application to Medical Care, February 2005

1408 Thorvaldur Gylfason, Interview with Assar Lindbeck, February 2005

1409 Christian Gollier, Some Aspects of the Economics of Catastrophe Risk Insurance, February 2005

1410 Gebhard Kirchgässner, The Weak Rationality Principle in Economics, February 2005

1411 Carlos José Fonseca Marinheiro, Has the Stability and Growth Pact Stabilised? Evidence from a Panel of 12 European Countries and Some Implications for the Reform of the Pact, February 2005 
1412 Petter Osmundsen, Frank Asche, Bård Misund and Klaus Mohn, Valuation of International Oil Companies -The RoACE Era, February 2005

1413 Gil S. Epstein and Shmuel Nitzan, Lobbying and Compromise, February 2005

1414 Marcel F. M. Canoy, Jan C. van Ours and Frederick van der Ploeg, The Economics of Books, February 2005

1415 Eric A. Hanushek and Ludger Wößmann, Does Educational Tracking Affect Performance and Inequality? Differences-in-Differences Evidence across Countries, February 2005

1416 George Kapetanios and M. Hashem Pesaran, Alternative Approaches to Estimation and Inference in Large Multifactor Panels: Small Sample Results with an Application to Modelling of Asset Returns, February 2005

1417 Samuel Mühlemann, Jürg Schweri, Rainer Winkelmann and Stefan C. Wolter, A Structural Model of Demand for Apprentices. February 2005

1418 Giorgio Brunello and Lorenzo Rocco, Educational Standards in Private and Public Schools, February 2005

1419 Alex Bryson, Lorenzo Cappellari and Claudio Lucifora, Why so Unhappy? The Effects of Unionisation on Job Satisfaction, March 2005

1420 Annalisa Luporini, Relative Performance Evaluation in a Multi-Plant Firm, March 2005

1421 Giorgio Bellettini and Carlotta Berti Ceroni, When the Union Hurts the Workers: A Positive Analysis of Immigration Policy, March 2005

1422 Pieter Gautier, Michael Svarer and Coen Teulings, Marriage and the City, March 2005

1423 Ingrid Ott and Stephen J. Turnovsky, Excludable and Non-Excludable Public Inputs: Consequences for Economic Growth, March 2005 